\title{
Effects of GC7101, a Novel Prokinetic Agent on Gastric Motor Function: Ex Vivo Study
}

\author{
Da Hyun Jung, ${ }^{1}$ Eun Ju Choi, ${ }^{1,3}$ Han Ho Jeon, ${ }^{1,3}$ Young Ho Lee ${ }^{2}$ and Hyojin Park ${ }^{1,3 *}$ \\ Departments of ${ }^{1}$ Internal Medicine and ${ }^{2}$ Physiology, ${ }^{3}$ Gangnam Severance Hospital, Yonsei University College of Medicine, Seoul, Korea
}

\begin{abstract}
Background/Aims
GC7101, an extract of Lonicera Flos, is a novel developing drug for reflux esophagitis and functional dyspepsia. However, the drug's exact pharmacological mechanism of action remains unclear. This study assessed the effects of GC7101 on gastrointestinal (GI) motor function.
\end{abstract}

\section{Methods}

We used male guinea pigs to evaluate the effects of GC7101 on Gl motility. The contraction of antral circular muscle in the presence of different doses of GC7101 was measured in a tissue bath. The prokinetic effects of GC7101 were tested using the charcoal transit assay from the pylorus to the most distal point of migration of charcoal mixture. To clarify the mechanism of action of GC7101, atropine, dopamine and the selective 5-hydroxytryptamine 4 receptor antagonist, GR113808 were used.

\section{Results}

The maximal amplitude of circular muscle contraction was induced by $5 \mathrm{mg} \mathrm{mL}^{-1} \mathrm{GC7101}$. The area under the curve of contraction was significantly increased at $5 \mathrm{mg} \mathrm{mL}^{-1} \mathrm{GC7101}$. Addition of $10^{-6} \mathrm{M}$ atropine, $10^{-8} \mathrm{M}$ dopamine or $10^{-7} \mathrm{M} \mathrm{GR}$ 113808 to GC7101 $5 \mathrm{mg} \mathrm{mL}^{-1}$ decreased the amplitude and area under curve compared to GC7101 $5 \mathrm{mg} \mathrm{mL}^{-1}$ alone. GC7101 accelerated GI transit in a dose dependent manner except $100 \mathrm{mg} \mathrm{kg}^{-1}$. Delayed $\mathrm{Gl}$ transit caused by atropine, dopamine and GR 113808 was restored by GC7101 $50 \mathrm{mg} \mathrm{kg}^{-1}$.

\section{Conclusions}

GC7101, an extract of Lonicera Flos, exerts a gastric prokinetic effect in guinea pig through cholinergic, antidopaminergic and serotonergic mechanisms. Therefore, GC7101 might be a novel drug for the treatment of functional dyspepsia.

\section{(J Neurogastroenterol Motil 2014;20:469-474)}

Key Words

Functional dyspepsia; Gastrointestinal motility; Lonicera Flos; Prokinetic

Received: February 8, 2014 Revised: June 13, 2014 Accepted: June 15, 2014

(c) This is an Open Access article distributed under the terms of the Creative Commons Attribution Non-Commercial License (http://creativecommons. org/licenses/by-nc/3.0) which permits unrestricted non-commercial use, distribution, and reproduction in any medium, provided the original work is properly cited.

*Correspondence: Hyojin Park, MD, PhD

Department of Internal Medicine, Gangnam Severance Hospital, Yonsei University College of Medicine, 211 Eonjuro, Gangnam-gu, Seoul 135-720, Korea

Tel: +82-2-2019-3318, Fax: +82-2-3463-3882, E-mail: hjpark21@yuhs.ac

Financial support: This study was supported by Green Cross Corp.

Conflicts of interest: None.

Author contributions: Da Hyun Jung, Eun Ju Choi and Han Ho Jeon, conception and design, or analysis and interpretation of data; Da Hyun Jung and Young Ho Lee, drafting the article or revising it critically for important intellectual content; Hyojin Park, final approval of the version to be published. 


\section{Introduction}

Functional dyspepsia (FD) is one of the most common gastrointestinal (GI) disorders, which is defined as occurrence of upper abdominal symptoms without organic causes. ${ }^{1}$ The prevalence of FD defined according to strict criteria is about $5-12 \%$. $^{2}$ The pathophysiology of FD is complex, with multiple factors implicated; however, abnormalities in GI motor function have been proposed as a major cause of FD. Abnormal gastric motility and visceral hypersensitivity are 2 major physiological abnormalities that cause FD. Other diverse factors such as genetic predisposition, a prior viral infection, stress, inflammation, Helicobacter pylori infection, abnormal secretion of gastric acid, psychological factors, diet and lifestyle could affect the pathogenesis of FD. ${ }^{3}$ Although FD is a very common disorder, it is difficult to manage. Among the medications used to treat $\mathrm{FD}$, prokinetics have shown efficacy in meta-analyses. ${ }^{4}$ However, the reliability of these studies is very low and the adverse effects of previous prokinetics were serious. Therefore, new drugs for the treatment of FD including mosapride, itopride and acotinamide have been developed, which show improvements of GI motility without adverse cardiovascular events. ${ }^{5}$ In this respect, the need of safer and more effective medications for the treatment of FD has increased. Thus, several herbal medicines were assessed for their potential to treat FD. ${ }^{6}$ For example, DA-9701, an extract from 2 herbs (Pharbitis Semen and Corydalis Tuber) has been reported to accelerate gastric emptying in normal rats and restore delayed emptying. DA-9701 also increased GI transit in controls and delayed gastric emptying models induced by laparotomy or atropine. $^{7}$ In addition, Kim et $\mathrm{al}^{8}$ showed that DA-9701 improved gastric accommodation by increasing the postprandial gastric volume in conscious dogs. At least 44 herbal products have been recommended for treatment of FD. ${ }^{6}$ A large number of herbal medicine clinical trials showed that patients receiving peppermint and caraway had improved symptoms by $60-95 \%$. GC7101 is a potential prokinetic agent which was obtained from extracts of Lonicera Flos (LF). It is a widely used herbal medication in China and is known to have latent-heat-clearing, antipyretic, antioxidant and anti-inflammatory actions. ${ }^{10} \mathrm{Ku}$ et al ${ }^{11}$ reported that the antioxidant properties of LF were effective in gastroesophageal reflux disease. They found that LF combated oxidative stress and free radical damage in esophageal and gastric mucosa in rat models. ${ }^{11}$ In addition, they found that LF promoted gastric motor function (unpublished data). There are no previous reports on the effects of LF on GI motor function. Therefore, we aimed to investigate the prokinetic effect of GC7101 on GI contraction and transit and to validate which mechanisms GC7101 exerts through ex vivo.

\section{Materials and Methods}

\section{Preparation of Animals}

Adult male Hartley guinea pigs (250-350 g, Orient Bio Inc., Seoul, Korea) were acclimated to their holding room (temperature controlled at $21 \pm 1^{\circ} \mathrm{C}, 50 \pm 10 \%$ humidity, and 12 hour light/dark cycle commencing at $7 \mathrm{AM}$ ). A standard guinea pig diet (7006 Teklad Guinea Pig Diet; Harlan laboratories) and drinking water were provided ad libitum. All experiments were conducted in accordance with the Guide for the Care and Use of Laboratory Animals provided by the Animal Laboratory Ethics Committee of the Department of Laboratory Animal Medicine, Medical Research Center, Yonsei University College of Medicine.

\section{Drugs}

The following drugs and chemicals were used; charcoal (Sigma, St. Louis, MO, USA), barium sulfate (Tae Joon Pharmaceuticals, Seoul, Korea), GC7101 (Green cross Corp, Yongin, Korea), atropine and dopamine (Sigma, St. Louis, MO, USA), and GR113808 (Tocris, Ellisville, MO, USA). They were freshly made for every experiment by dissolving each compound in isotonic sodium chloride solution.

\section{Experimental Design: The Effects of GC7101 on Antral Circular Muscle Contraction}

Antral circular muscle was removed and cut into 3-mm wide and 10-mm long fragments and the lumen flushed clean using Krebs-Henseleit $(\mathrm{K}-\mathrm{H})$ solution which was maintained at $37^{\circ} \mathrm{C}$, $\mathrm{pH} 7.4$ and saturated with $95 \% \mathrm{O}_{2}$ and $5 \% \mathrm{CO}_{2}$ in a chamber. The circular muscle was fixed and connected to independent tension transducers (BIOPAC TSD 105; BIOPAC Systems, Inc., Santa Barbara, CA, USA). The preparation was set up and allowed to equilibrate for at least 60 minutes after $1 \mathrm{~g}$ resting tension. Circular muscle activity was quantified by means of a computerized integration procedure (BIOPAC MP 100; BIOPAC Systems, Inc.). GC7101 (0.01-10 $\mathrm{mg} \mathrm{mL}^{-1}$ ) was added to the bath solution for 5 minutes without washing between successive changes in concentration. Drugs including GC7101, atropine, dopamine and GR113808, a selective 5-hydroxytrypt- 
A

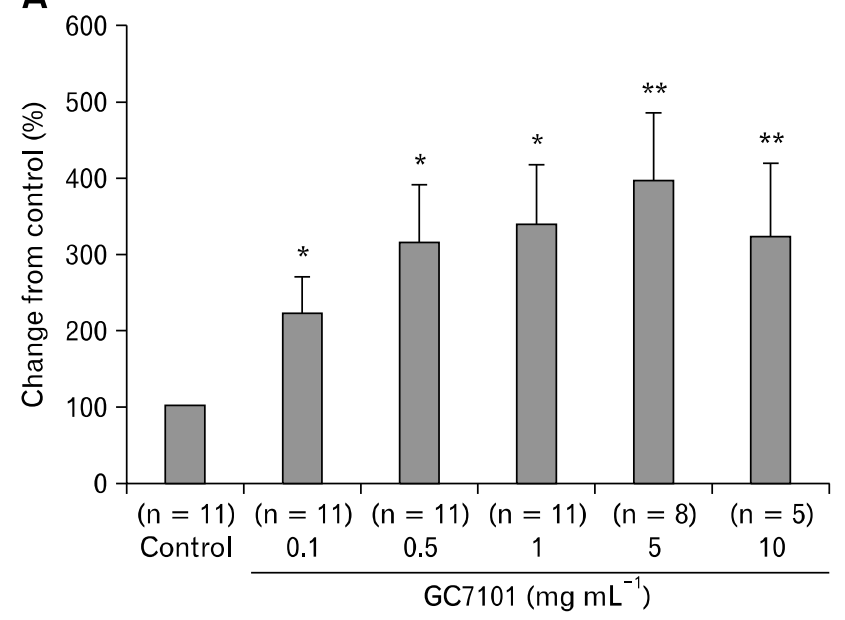

B

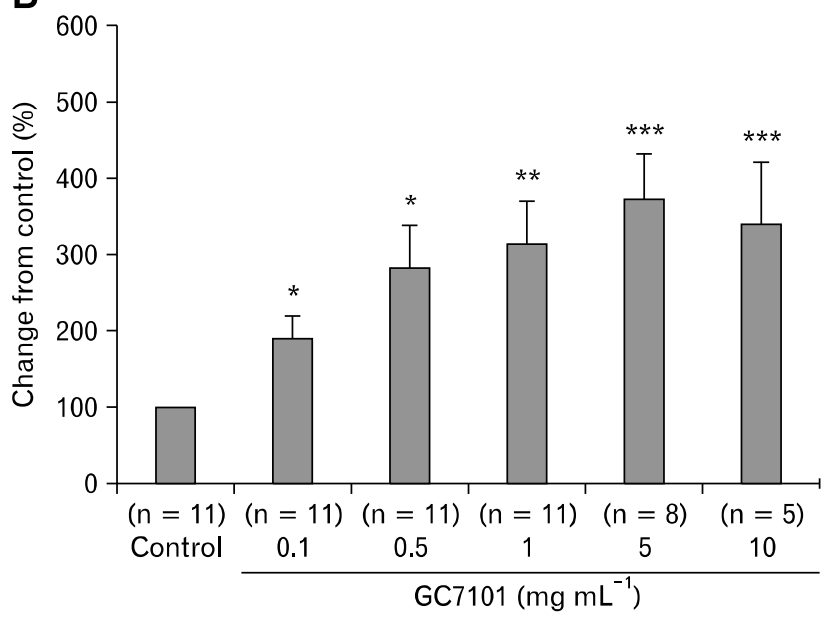

Figure 1. Effects of GC7101 on contraction of stomach antral muscle. GC7101 increased maximal amplitude and area under the curve in a dose dependent manner $\left(0.1-10 \mathrm{mg} \mathrm{mL}^{-1}\right)$. (A) Maximal amplitude $\left(\%\right.$ control). ${ }^{*} P=0.010,{ }^{* *} P<0.001$ compared with control levels. (B) Area under the curve (\% control). ${ }^{*} P=0.010,{ }^{* *} P<0.001$ and ${ }^{* *} P=0.001$ compared with control levels. Values are mean $\pm \mathrm{SE}$.
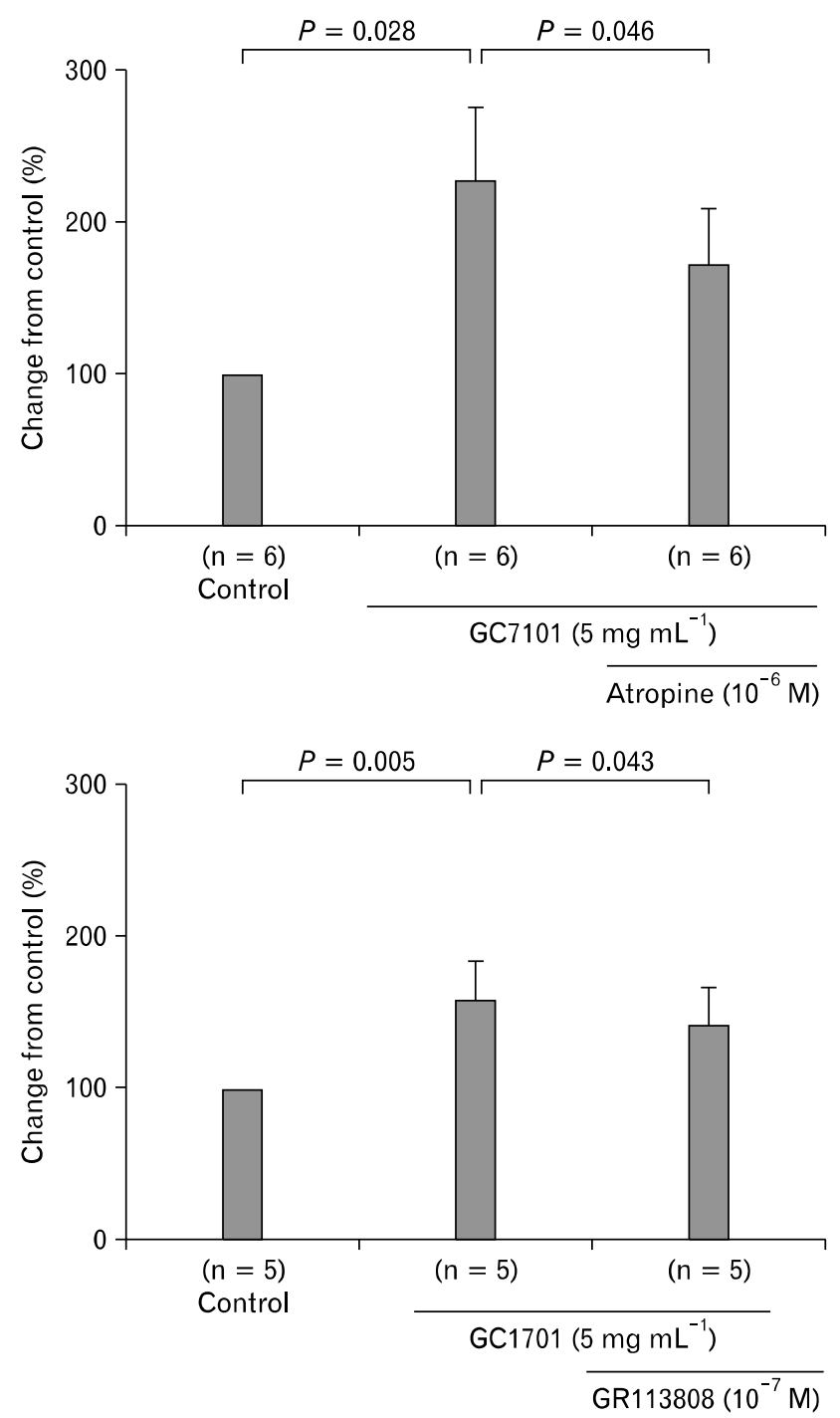

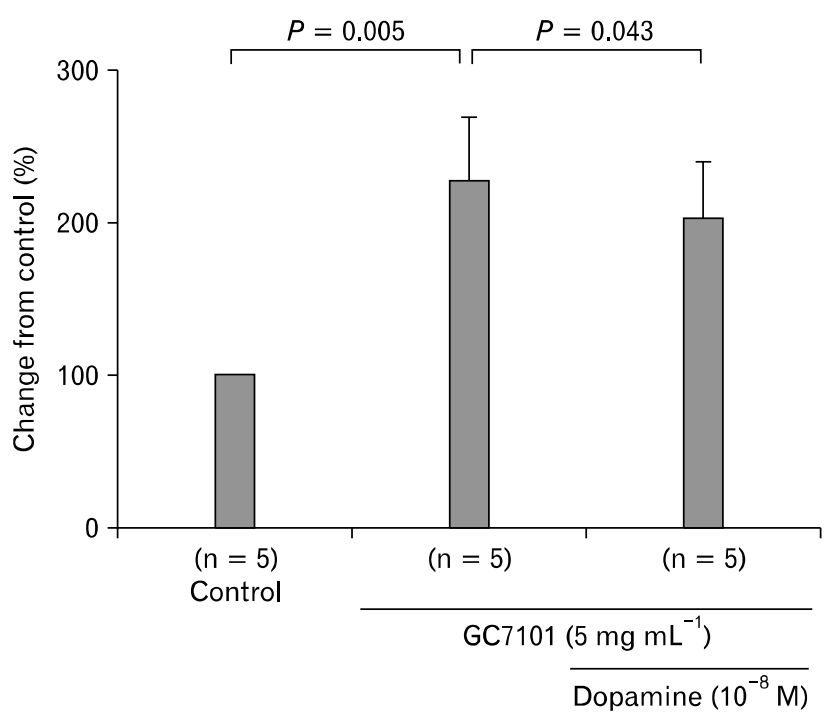

Figure 2. Effects of atropine, dopamine, and GR113808 on contraction of GC7101-treated stomach antral muscle. Addition of $10^{-6} \mathrm{M}$ atropine, $10^{-8} \mathrm{M}$ dopamine or $10^{-7} \mathrm{M}$ GR113808 to GC71015 mg $\mathrm{mL}^{-1}$ decreased the amplitude of contraction with GC7101 alone. Values are mean $\pm \mathrm{SE}$. 
amine $4\left(5-\mathrm{HT}_{4}\right)$ receptor antagonist, were added to the chamber. The maximal amplitude and area under the curve (AUC) of the antral muscle contraction were obtained to evaluate the effects of drugs on GI motility.

\section{Experimental Design: The Effects of GC7101 on Charcoal Transit}

After being fasted for 24 hours with free access to water, guinea pigs received atropine $0.1 \mathrm{mg} \mathrm{kg}^{-1}$, dopamine $0.4 \mathrm{mg} \mathrm{kg}^{-1}$ or GR $1138081 \mathrm{mg} \mathrm{kg}^{-1}$ via orogastric cannula. After 30 minutes, GC7101 was administered via orogastric cannula, followed by $2.5 \mathrm{~mL}$ of a charcoal mixture after another 30 minute wait. The charcoal mixture consisted of charcoal, barium, and normal saline in a 1:2:6 ratio. The guinea pigs were sacrificed by blow to the occipital region and severing the carotid arteries. The abdomens were opened and the intestines were removed from the pyloric junction to the ileocecal valve. Upper GI transit was evaluated as the migration of charcoal mixture from the pylorus to the most distal point of migration, and expressed as a percentage (\%) of charcoal migration $(\mathrm{cm})$ to the length of total small intestine $(\mathrm{cm})$ 5 minutes after injection of the charcoal mixture.

\section{Statistical Methods}

Results for each variable were expressed as percentage of control levels. Statistical analysis was performed using repeated measures ANOVA with post hoc comparison or the Mann-Whitney $U$ test. In all tests, statistical significance was assigned if $P<0.05$ based on the mean. Values are means with standard error. All data were analyzed using SPSS version 12.0 for Windows software (SPSS Inc., Chicago, IL, USA).

\section{Results}

\section{Effects of GC7101 on Contraction of Stomach Antral Muscle}

The amplitude of circular muscle contraction increased in a dose dependent manner from 0.1 to $5 \mathrm{mg} \mathrm{mL}^{-1}$ (except $10 \mathrm{mg}$ $\mathrm{mL}^{-1}$ ) GC7101. The maximal amplitude of the circular muscle contractions were $221.4 \pm 49.7 \%, 315.7 \pm 76.4 \%, 338.5 \pm$ $80.2 \%, 396.8 \pm 89.2 \%$ and $324.9 \pm 94.2 \%$ in the presence of $0.1,0.5,1,5$ and $10 \mathrm{mg} \mathrm{mL}^{-1}$ GC7101, respectively. The maximal amplitude of the circular muscle contraction was induced by $5 \mathrm{mg} \mathrm{mL}^{-1}$ GC7101 (Fig. 1A). The AUC of the circular muscle contraction also increased in a dose dependent manner with 0.1 to
$5 \mathrm{mg} \mathrm{mL}^{-1}$ (except $10 \mathrm{mg} \mathrm{mL}^{-1}$ ) GC7101. The AUC of the circular muscle contractions were $190.2 \pm 32.4 \%, 282.8 \pm$ $56.3 \%, 312.8 \pm 57.9 \%, 373.3 \pm 58.4 \%$ and $339.2 \pm 84.4 \%$ in the presence of $0.1,0.5,1,5$ and $10 \mathrm{mg} \mathrm{mL}^{-1} \mathrm{GC7101}$, respectively. The maximal AUC of the circular muscle contraction was induced by $5 \mathrm{mg} \mathrm{mL}^{-1}$ GC7101 (Fig. 1B). Addition of $10^{-6} \mathrm{M}$ atropine, $10^{-8} \mathrm{M}$ dopamine, or $10^{-7} \mathrm{M}$ GR 113808 to GC7101 $5 \mathrm{mg} \mathrm{mL}^{-1}$ decreased the amplitude compared to GC7101 alone (228.4 $\pm 48.5 \%$ vs. $171.5 \pm 38.1 \%, P=$ $0.046 ; 228.4 \pm 40.3 \%$ vs. $202.6 \pm 36.8 \%, P=0.043 ; 157.6 \pm$ $26.3 \%$ vs. $141.3 \pm 24.7 \%, P=0.043$; respectively) (Fig. 2).

\section{Effects of GC7101 on the Transit of Charcoal}

The average charcoal transit was $35.1 \pm 5.6 \%$ in the control group. The percentage $(\%)$ of the migration length $(\mathrm{cm})$ of charcoal to total small intestine $(\mathrm{cm})$ was $46.4 \pm 7.9 \%$, $55.9 \pm 4.1 \%$ and $20.1 \pm 6.8 \%$ in $25 \mathrm{mg} \mathrm{kg}^{-1}, 50 \mathrm{mg} \mathrm{kg}^{-1}$ and $100 \mathrm{mg} \mathrm{kg}^{-1}$ GC7101, respectively $(P=0.002)$. In normal guinea pigs, GC7101 accelerated GI transit of charcoal in a dose dependent manner except the $100 \mathrm{mg} \mathrm{kg}^{-1}$ dose. The maximal charcoal transit was induced by $50 \mathrm{mg} \mathrm{kg}^{-1} \mathrm{GC7101}$ ( $P=0.030$ compared to the control). However, the charcoal transit slightly decreased with $100 \mathrm{mg} \mathrm{kg}^{-1}$ GC7101 (Fig. 3). Subsequently, we used the delayed model of GI transit to assess whether GC7101 is able to reverse abnormally delayed GI transit. Delayed charcoal transit after administration of atropine $0.1 \mathrm{mg} \mathrm{kg}^{-1}$, dopamine

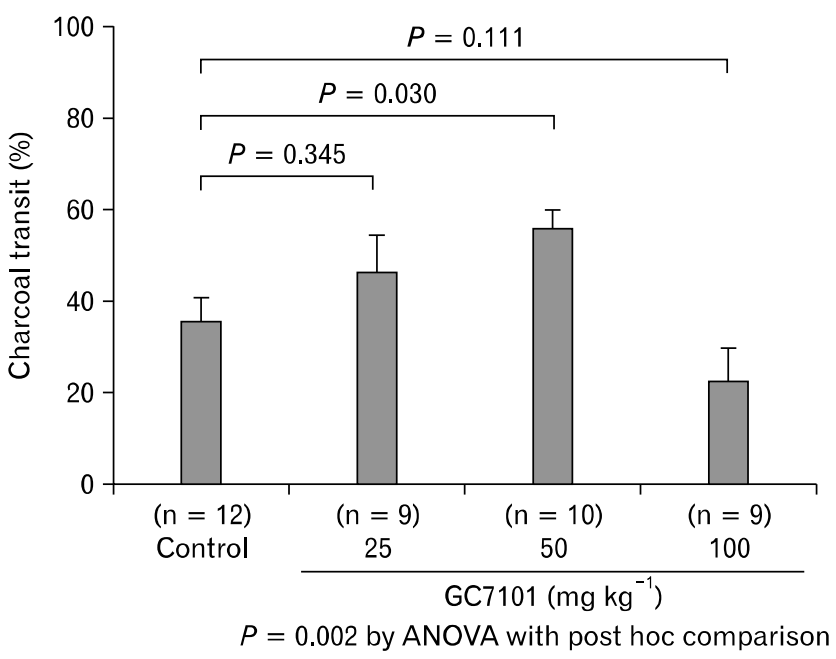

Figure 3. The effects of GC7101 assessed by migration of charcoal. GC7101 accelerated gastrointestinal transit of charcoal in a dose dependent manner except $100 \mathrm{mg} \mathrm{kg}^{-1}$. Values are mean $\pm \mathrm{SE}$. 

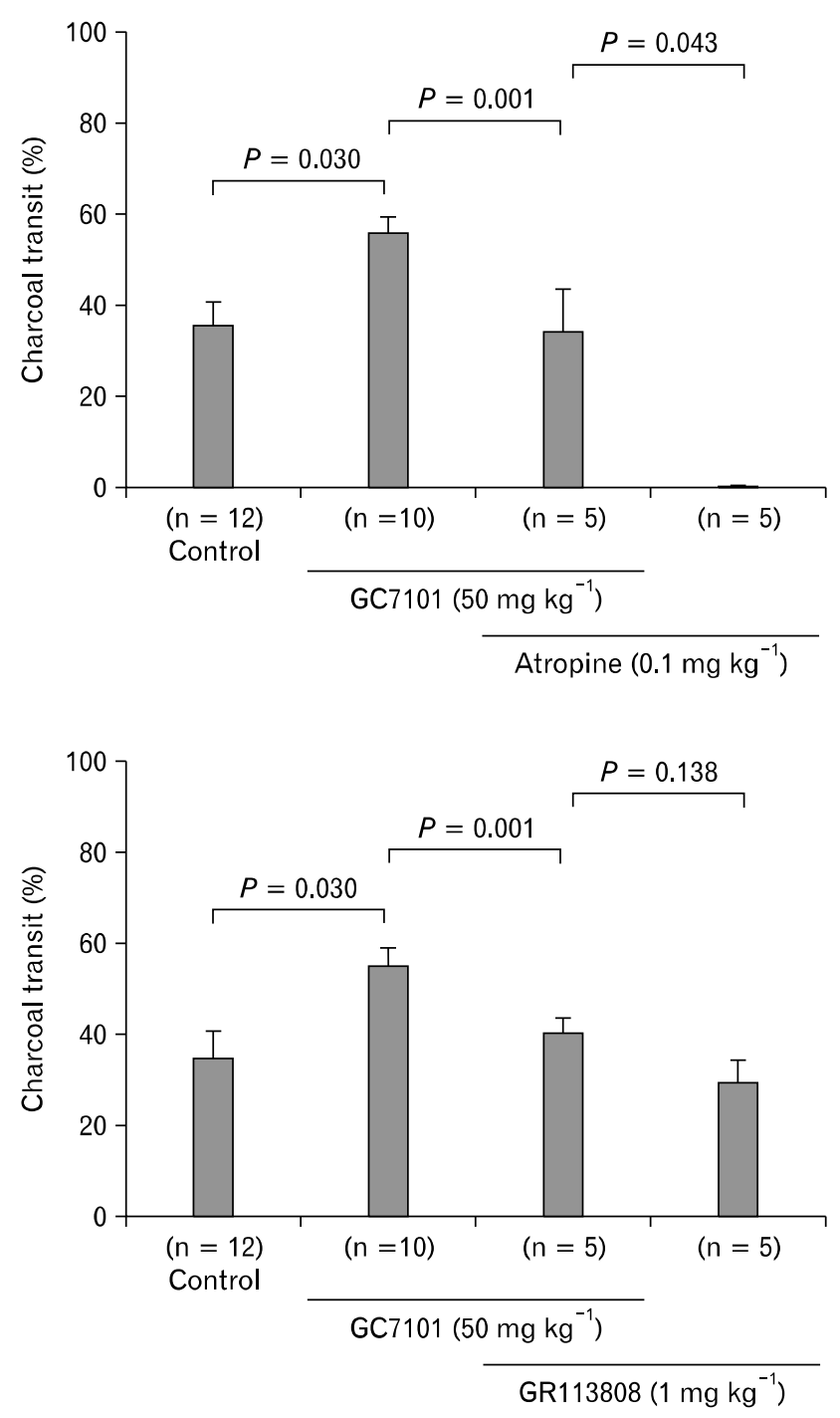

$0.4 \mathrm{mg} \mathrm{kg}^{-1}$ or GR113808 $1 \mathrm{mg} \mathrm{kg}^{-1}$ was restored by GC7101 at a dose of $50 \mathrm{mg} \mathrm{kg}^{-1}$ (Fig. 4). These results showed that GC7101 not only accelerated GI transit in normal conditions, but furthermore restored delayed GI transit induced by atropine, dopamine or GR113808.

\section{Discussion}

FD is a chronic and highly prevalent GI disorder that imposes a large amount of healthcare cost on patients. Therefore, many studies are ongoing to identify therapeutic agents for FD. Prokinetics are known to be helpful for relieving the symptoms of FD. However, their application is very limited due to several factors including ineffectiveness and potentially fatal side effects. As the demands of more safe and effective medications for FD in-

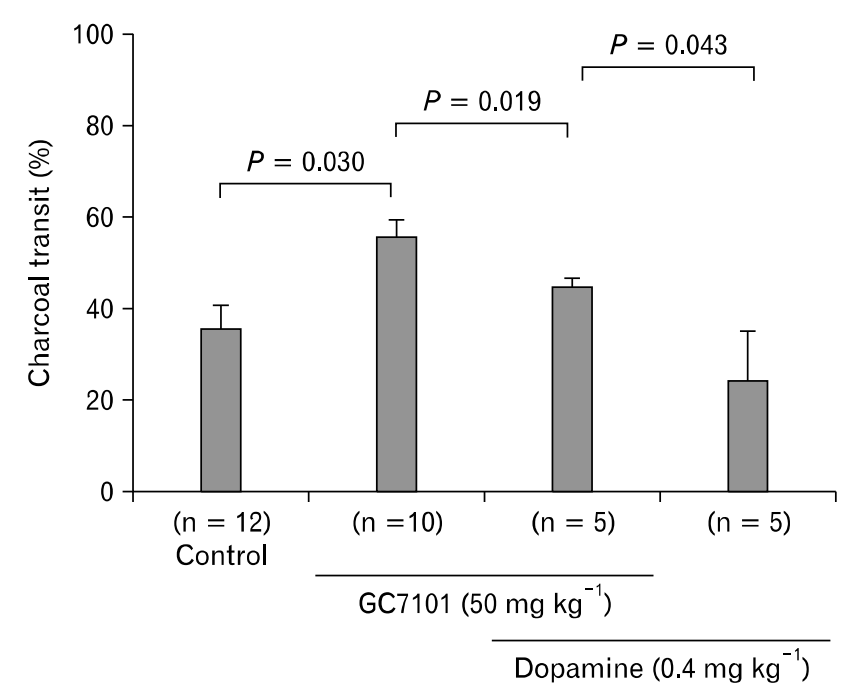

Figure 4. The effects of GC7101 on altered gastrointestinal transit induced by atropine, dopamine or GR113808. Delayed charcoal transit after administration of atropine or dopamine was restored by $\mathrm{GC} 7101$ at $50 \mathrm{mg} \mathrm{kg}^{-1}$. Values are mean $\pm \mathrm{SE}$.

creased, several herbal medicines have been evaluated for their potential use. GC7101 is an extract of LF which is a widely prescribed herbal medicine in China. However, the pharmacological effects of LF on GI motor function have not been studied yet. There was one report that application of the Chinese herbal recipe composed of multiple plants and roots including LF could effectively promote postoperative recovery of GI motility. ${ }^{12}$ For the first time, we showed that GC7101 has effects on GI motor function assessed by gastric antral contraction and GI transit. It implies that GC7101 is a potential candidate to treat FD with delayed gastric emptying. GI transit and gastric antral contraction are well established models to assess prokinetic effects. Atropine has inhibitory effects on GI motility by acting as a competitive antagonist of the acetylcholine receptors. Dopamine and GR 113808 also delay GI motility through dopamine receptors and 
antagonism of $5-\mathrm{HT}_{4}$-receptors, respectively. Dopamine decreases motility of the GI tract, whereas dopamine antagonists increase peristaltic contraction of the esophageal muscles and improve GI motor activity. ${ }^{13}$ Selective $5-\mathrm{HT}_{4}$ receptor agonists has been shown to enhance gastric accommodation and accelerate gastric emptying and GI transit. ${ }^{14}$ GC7101 could restore the delayed GI transit caused by atropine, dopamine, or GR113808. The increased contraction by GC7101 was inhibited by atropine, dopamine, or GR113808. Taken together, GC7101 enhances GI motor function by acting on cholinergic, antidopaminergic, and serotonergic mechanisms. These results showed that GC7101 could enhance GI motility both in normal or abnormal conditions and identify a possible novel therapeutic agent of FD.

In conclusion, GC7101 which is an extract from LF, exerts a gastric prokinetic effect in guinea pigs through multiple mechanisms including cholinergic, antidopaminergic and serotonergic mechanism. Further studies are definitely warranted to prove the therapeutic use of GC7101 in FD through highly qualified and controlled clinical trials.

\section{References}

1. Miwa H, Ghoshal UC, Fock KM, et al. Asian consensus report on functional dyspepsia. J Gastroenterol Hepatol 2012;27:626-641.

2. El-Serag HB, Talley NJ. Systemic review: the prevalence and clinical course of functional dyspepsia. Aliment Pharmacol Ther 2004;19: 643-654

3. Miwa H. Why dyspepsia can occur without organic disease: patho- genesis and management of functional dyspepsia. J Gastroenterol 2012;47:862-871.

4. Moayyedi P, Soo S, Deeks J, Delaney B, Innes M, Forman D. Pharmacological interventions for non-ulcer dyspepsia. Cochrane Database Syst Rev 2006;(2):CD001960.

5. Tack J, Masclee A, Heading R, et al. A dose-ranging, placebo-controlled, pilot trial of Acotiamide in patients with functional dyspepsia. Neurogastroenterol Motil 2009;21:272-280.

6. Thompson Coon J, Ernst E. Systematic review: herbal medicinal products for non-ulcer dyspepsia. Aliment Pharmacol Ther 2002;16: 1689-1699.

7. Lee TH, Choi JJ, Kim DH, et al. Gastroprokinetic effects of DA-9701, a new prokinetic agent formulated with Pharbitis Semen and Corydalis Tuber. Phytomedicine 2008;15:836-843.

8. Kim ER, Min BH, Lee SO, Lee TH, Son M, Rhee PL. Effects of DA-9701, a novel prokinetic agent, on gastric accommodation in conscious dogs. J Gastroenterol Hepatol 2012;27:766-772.

9. Saad RJ, Chey WD. Review article: current and emerging therapies for functional dyspepsia. Aliment Pharmacol Ther 2006;24:475-492.

10. Lan W, Zhaojun Z, Zesheng Z. Characterization of antioxidant activity of extracts from Flos Lonicerae. Drug Dev Ind Pharm 2007;33: 841-847.

11. Ku SK, Seo BI, Park JH, et al. Effect of Lonicerae Flos extracts on reflux esophagitis with antioxidant activity. World J Gastroenterol 2009;15:4799-4805.

12. Xu L, Jiang J, Du FZ. Application of dannang recipe no. 2 in the perioperative stage of laparoscopic cholecystectomy. Zhongguo Zhong Xi Yi Jie He Za Zhi 2008;28:1090-1092.

13. Tack J. Prokinetics and fundic relaxants in upper functional GI disorders. Curr Opin Pharmacol 2008;8:690-696.

14. Gershon MD, Tack J. The serotonin signaling system: from basic understanding to drug development for functional GI disorders. Gastroenterology 2007;132:397-414. 